\title{
Finite Element Analyses of Low Velocity Impact on Thin Composite Disks
}

\author{
Marcelo L. Ribeiro" ${ }^{1}$, Ricardo Afonso Agélico², Ricardo de Medeiros², Volnei Tita,", \\ ${ }^{1}$ Aerospace Engineering, Federal University of Santa Catarina, Joinville Campus, Brazil \\ ${ }^{2}$ Department of Aeronautical Engineering, São Carlos School of En gineering, University of São Paulo, São Carlos, Brazil
}

\begin{abstract}
The prediction of dynamic behavior for composite laminates is very complex, because of many concurrent phenomena can take place during impact load. Fiber breakage, dela minations, matrix cracking, plastic deformations due to contact and large displacements are some effects. Thus, in this work, some mechanisms are simulated by using a new failure model, which considers five failure modes: two for fiber-failure (FF) and three for inter-fiber-failure (IFF). For FF modes, the ply fails under longitudinal tension or compression. For IFF modes, the ply fails under shear stress combined to transverse tension (Mode A) or transverse compression stress (Mode B or C). Each failure mode has a failu re criteria and an associated degradation function, which decreases the engineering material properties, requiring an iterative procedure for the process of failure analysis. The material model is implemented as sub-routines written in Fortran (UMAT and VUMAT), which are linked to Abaqus ${ }^{\mathrm{TM}}$. First, the material model parameters were identified based on experimental tests. Second, two parameters were calibrated by using three-point bending tests and implicit numerical simulations with UMAT sub-routine. A computational program in Matlab was developed in order to control the calibration process and the post-processing of the results. After calibration procedure, the material model proposal was applied to pred ict the response of thin composite disks under impact loads. The finite element analyses via VUMAT were carried out considering the influence not only of the torque value on the screws of the composite disk fixation device, but also the friction coefficient between the composite disk and the fixation device. Finally, the finite element results were compared to experimental data and it was discussed the advantages and limitation of the material model proposal.
\end{abstract}

Keywords Composite Laminates, Material Model, Low Velocity Impact, Finite Element Analysis

\section{Introduction}

During the last years, criteria of aircraft projects have been more and more rigorous for structural components, which are developed to absorb impact energy. Numerical and experimental investigations about the development of structural components with high crashworthiness have been carried out by the aeronautical industries. In fact, the project concept for structural components with high crashworthiness depends on the crash resistance concept described by Kindervater and Georgi[1]. The crash resistance concept is based on the energy absorption capacity and structural integrity. However, the prediction of dynamic behavior for composite laminates is very complex, because of many concurrent phenomena can take place during impact load. Fiber breakage, delaminations, matrix cracking, plastic deformations due to the contact and large displacements are some effects, which should be considered

* Corresponding author:

voltita@sc.usp.br (Volnei Tita)

Published online at http://journal.sapub.org/cmaterials

Copyright (C) 2013 Scientific \& Academic Publishing. All Rights Reserved when a structure made of composite material is impacted by a foreign object. Therefore, it is very common to find many research works about this issue at the literature, for example: Sari et al.[2], Ribeiro et a1.[3] and Tita et al.[4].

In this work, each failure mode has a failure criterion and an associated degradation function, which decreases the engineering material properties, requiring an iterative procedure for the process of failure analysis (Progressive Failure Analyses - PFA). Thus, a material model proposal was implemented as Fortran sub-routines (UMAT and VUMAT) linked to finite element package Abaqus ${ }^{\mathrm{TM}}$ for implicit and explicit numerical simulations. First, the material model parameters were identified based on experimental tests described at the literature. Second, two parameters were calibrated by using three-point bending tests and implicit numerical simulations with UMAT sub-routine. Therefore, Finite Element (FE) analyses were performed for a set of parameters. A computational program in Matlab was developed in order to control the calibration process and the post-processing of the results. After calibration procedure, the material model proposal was applied to predict the response of thin composite disks under impact loads, using explicit numerical simulations 
with VUMAT sub-routines. The finite element analyses were carried out, considering the influence not only of the torque value on the screws of the composite disk fixation device, but also the friction coefficient between the composite disk and the fixation device. Finally, the fin ite element results were compared to experimental data and it was discussed the advantages and limitation of the material model proposal.

\section{Material Model}

The material model proposal in this work is a new combination ofd ifferent failure criteria and degradation laws developed by other researchers. This approach combines the advantages of different models. For example, Hashin's theory[5] has a good performance to identify fiber failure. On the other hand, Puck and Schürmann's model[6-7] perform good predictions for inter fiber failure. Furthermore, the Matzenmiller's degradation law[8] is a good strategy for fiber direction. Moreover, there is a new method for calibration of material model parameters.

\subsection{Mathe matical For mul ation}

The material model proposal considers five failure modes for the composite material, which can be divided in two major groups: Fiber Failure (FF) and Inter-Fiber Failure (IFF). The material model criteria for fiber failure (FF) are based on Hashin's Theory[5]. The material model criteria for inter-fiber failure (IFF) are based on Puck's Theory[6-7]. Fiber failure criteria are evaluated for tensile loads (FF-T) and for compressive loads (FF-C) in direction 1. Inter-fiber failure criteria are evaluated for three failure modes: Mode-A (IFF-A), Mode-B (IFF-B) and Mode-C (IFF-C). It is important to highlight that the Puck's work nomenclature is used in th is paper, i.e. $\|$ is related to the direction of the fibers and $\perp$ is associated to the transverse direction of the fibers. The IFF modes consider that the failure occurs in the plane 2-3 as shown by Figure 1. IFF-A mode is caused by shear and transverse tensile stress. IFF-B and IFF-C modes are produced by shear and transverse compressive stress.

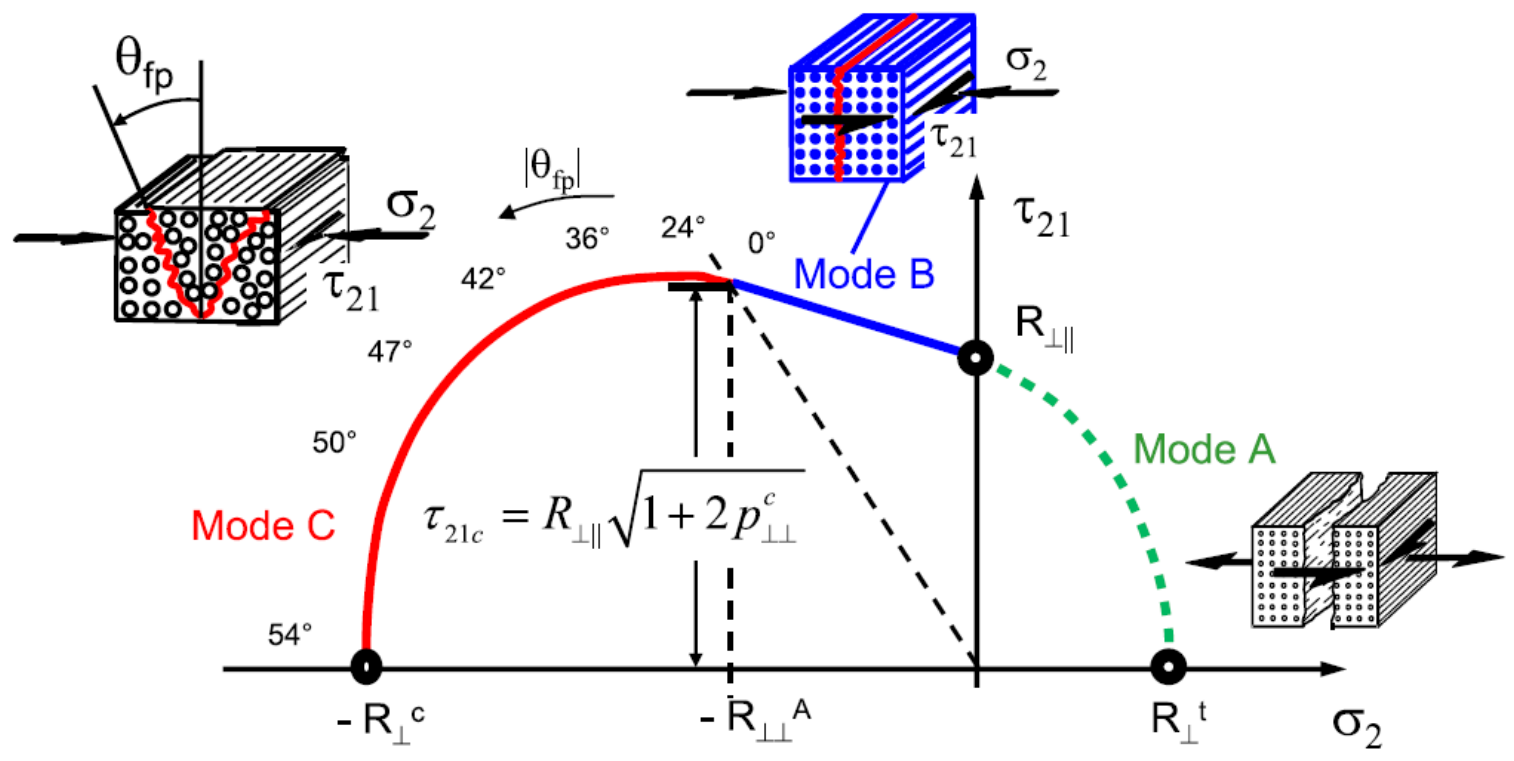

Figure 1. Failure surfaces for IFF Mode

Table 1 can summarize the equations and parameters as sociated to the material model proposal. The actuating plane stress state determined by the constitutive equations is verified by using the failure criteria and the allowable stresses. Each failure criterion gives a value, and if this value is greater than the unit, then it indicates the material failure. Thus, once it is verified the failure in a material point, i.e. the failure index $f_{F F}>1$ or $f_{I F F}>1$, the material properties of this region of the continuum needs to be reduced as a consequence of the failure mode. Thus, associated to each failu re mode, there are degradation laws where mechanical properties are decreased based on experimental observations. For FF failure modes, the longitudinal Young's Modulus $\left(\mathrm{E}_{1}\right)$ is reduced according to the para meter $\omega$, considering the Matzen miller's Theory [8], and the transverse properties $\left(\mathrm{E}_{2}, v_{12}\right.$ and $\left.\mathrm{G}_{12}\right)$ are assumed to be zero (Table 1). If the ply fails under IFF modes, then the longitudinal properties are not changed, but the $E_{2}$ and $G_{12}$ are decreased according to the parameter $\eta$ established by the Puck and Schürmann's work[6-7] (Table 1). As it is observed, the material properties are reduced when FF or IFF take place. Then, considering a Progressive Failure Analyses, this reduction can influence the FF or the IFF process in the next step. Thus, it is possible to mention that there is certain interaction between fiber failure and inter-fiber failure. 
Table 1. Summary of the material model proposal: failure criteria and degradation laws

\begin{tabular}{|c|c|c|c|}
\hline \multicolumn{4}{|c|}{ FAILURE CRITERIA } \\
\hline $\mathbf{F F}$ & \multicolumn{3}{|c|}{$\begin{array}{l}\text { FF-T: Fiber failure under tensile stress }\left(\sigma_{11}>0\right) \\
\qquad f_{F F}=\left(\frac{\sigma_{11}}{F_{1 T}}\right)^{2}+\left(\frac{\sigma_{12}}{F_{12}}\right)^{2} \\
\text { FF-C: Fiber failure under compressive stress }\left(\sigma_{11}<0\right) \\
\qquad f_{F F}=\left(\frac{\sigma_{11}}{F_{1 C}}\right)^{2}\end{array}$} \\
\hline IFF & $\begin{array}{r}\mathbf{I F} \\
f_{I F F}=\sqrt{\left[\left(\frac{1}{l}\right.\right.} \\
\text { FF-B: Inter-fiber fail } \\
f_{I F F}= \\
\text { FF-C: Inter-fiber fail } \\
f_{I F F}=\end{array}$ & $\begin{array}{l}\text {-A: Inter-fiber fai } \\
\left.\left.\perp-\frac{p_{\perp \| 1}^{t}}{R_{\perp \mid 1}}\right) \cdot \sigma_{22}\right] \\
\text { re - Mode B }\left(\sigma_{22}\right. \\
\left(\frac{\sigma_{12}}{R_{\perp \|}}\right)^{2}+\left(\frac{p_{\perp}^{c}}{R}\right. \\
\text { re - Mode C }\left(\sigma_{22}\right. \\
{\left[\left(\frac{\sigma_{12}}{2\left(1+p_{\perp \perp}^{c}\right) R_{\perp \mid 1}}\right)\right.}\end{array}$ & $\begin{array}{l}\text { e - Mode A } \\
+\left(\frac{\sigma_{12}}{R_{\perp \mid 1}}\right)^{2}+\frac{p_{\perp}^{t}}{R_{\perp \mid}} \sigma_{22} \\
\left.0 e\left|\sigma_{22} / \sigma_{12}\right| \leq\left|R_{\perp \perp}^{A} / \sigma_{12,0}\right|\right) \\
\left.\sigma_{22}\right)^{2}+\frac{p_{\perp}^{c}}{R_{\perp||}} \sigma_{22} \\
\left.0 e\left|\sigma_{22} / \sigma_{12}\right| \geq\left|R_{\perp \perp}^{A} / \sigma_{12,0}\right|\right) \\
\left.+\left(\frac{\sigma_{22}}{R_{\perp}^{c}}\right)^{2}\right] \frac{R_{\perp}^{c}}{-\sigma_{22}}\end{array}$ \\
\hline \multicolumn{4}{|c|}{ DEGRADATION LAWS } \\
\hline & Original Properties & & aded properties \\
\hline $\mathbf{F F}$ & $\begin{array}{l}E_{1} \\
E_{2} \\
G_{12} \\
\nu_{12}\end{array}$ & $\begin{array}{c}\overline{E_{1}}=(1-\omega) E_{1} \\
\overline{E_{2}}=0 \\
\overline{G_{12}}=0 \\
\overline{\nu_{12}}=0\end{array}$ & $\omega=1-\exp \left[-\frac{1}{m \varepsilon}\left(\frac{\varepsilon_{11}}{\varepsilon_{f}}\right)^{m}\right]$ \\
\hline IFF & $\begin{array}{l}E_{1} \\
E_{2} \\
G_{12} \\
\nu_{12}\end{array}$ & $\begin{array}{c}\overline{E_{1}}=E_{1} \\
\overline{E_{2}}=\eta_{E} E_{2} \\
\overline{G_{12}}=\eta_{G} G_{12} \\
\overline{\nu_{12}}=\nu_{12}\end{array}$ & $\eta=\frac{1-\eta_{r}}{1+c\left(f_{F F}-1\right)^{\xi}}+\eta_{r}$ \\
\hline
\end{tabular}

Figure 2 shows the parameters variation (e and $m$ ) for composite specimens made of unid irectional (UD) prepreg M10[4, 9], using the degradation law of FF mode.
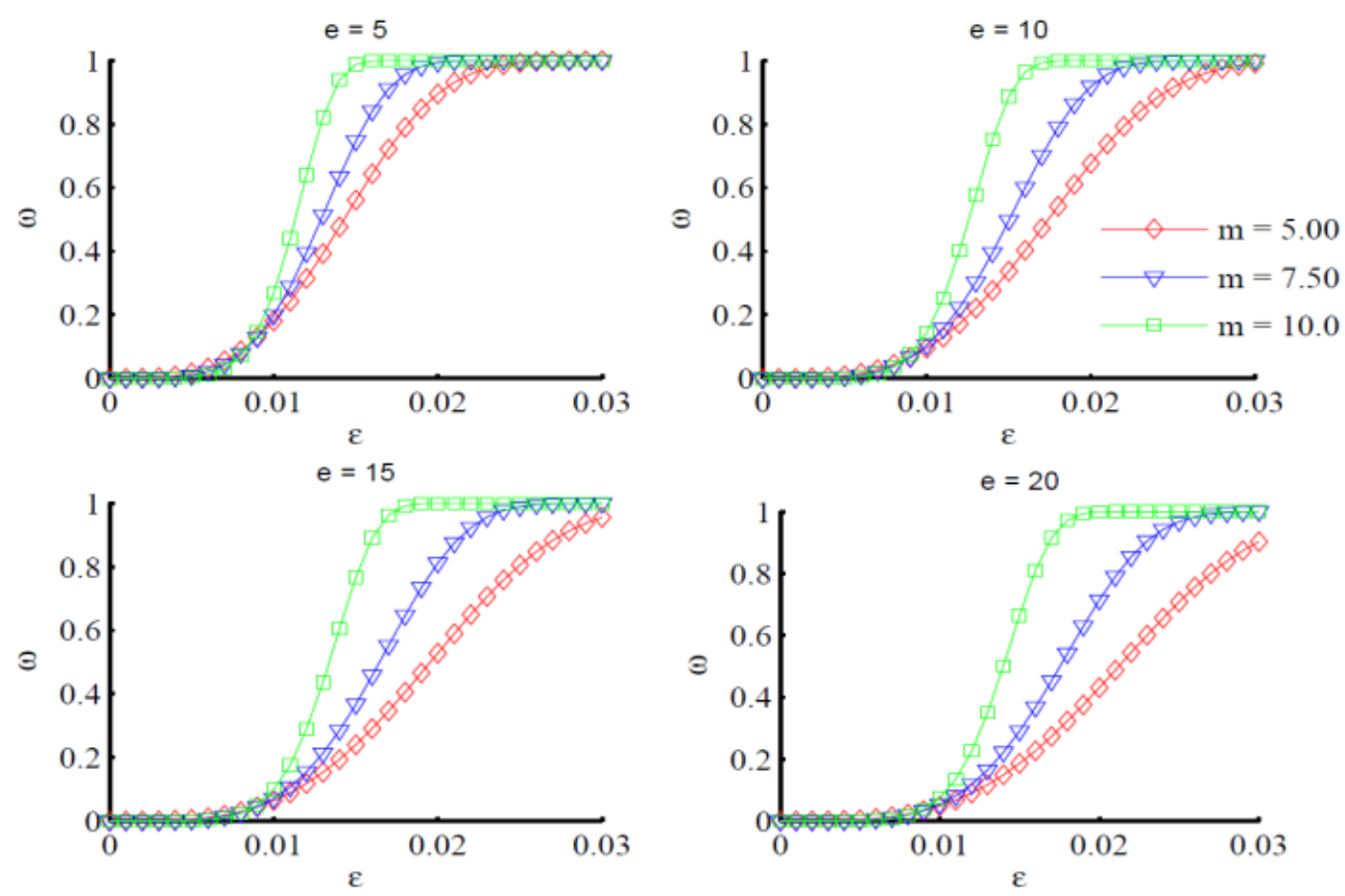

Figure 2. Parameters variation $e$ and $m$ in function of strain: composite specimens made of UD prepreg M10 
As observed in the Figure 2, it was necessary to use experimental data to identify the parameters $e$ and $m$. After some calculi based on the experimental results for[0 $]_{10}$ uniaxial tensile tests of UD prepreg M 10, the parameters $e$ equal 9.5 and $m$ equal 3.8 showed a good correlation between the fit curve and the experimental results [4, 9] as shown by Figure 3(a). Due to the difficult to obtain the complete experimental test curves for compression loadings, the material model parameters were identified using the value of ultimate compression stress, which is equal $930 \mathrm{MPa}[4,9]$. Thus, the parameters value of $e$ equal 16.0 and $m$ equal 4.7 have shown to perform the best fit for the compression part of the curve as shown by Figure 3(a).

Figure 3(b) shows the degradation variables related to IFF modes. The para meters $\eta_{E}$ and $\eta_{G}$ depend on the failu re index $f_{I F F}$. Since the UD prepreg M10 consist on a composite made of epoxy res in reinforced by unidirectional carbon fiber, it was used the same values obtained by Puck and Sührmann for carbon-epoxy co mposite specimens [7].

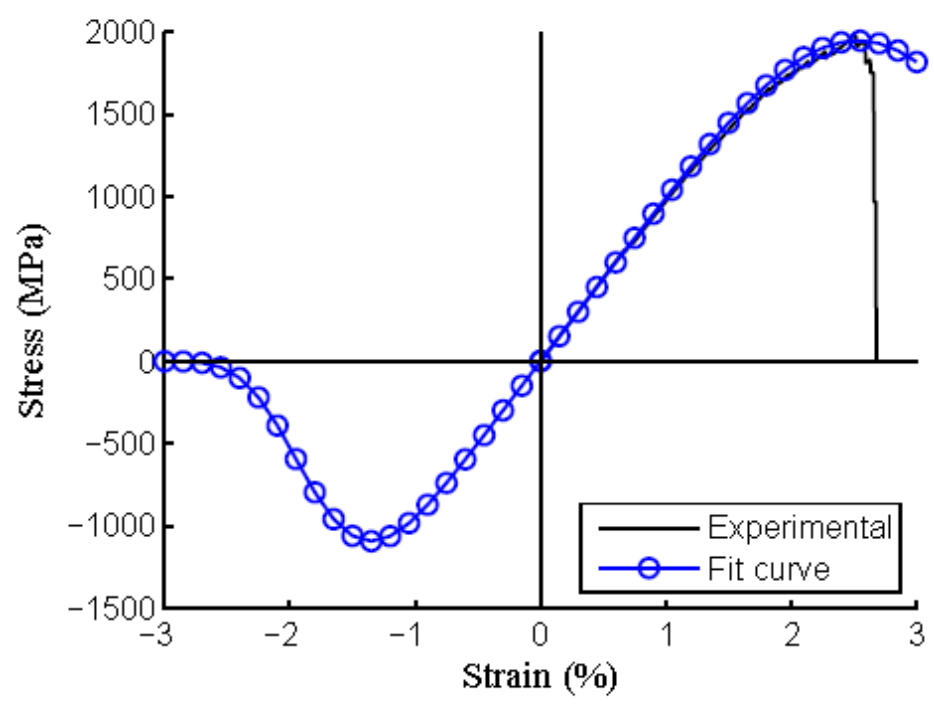

(a)

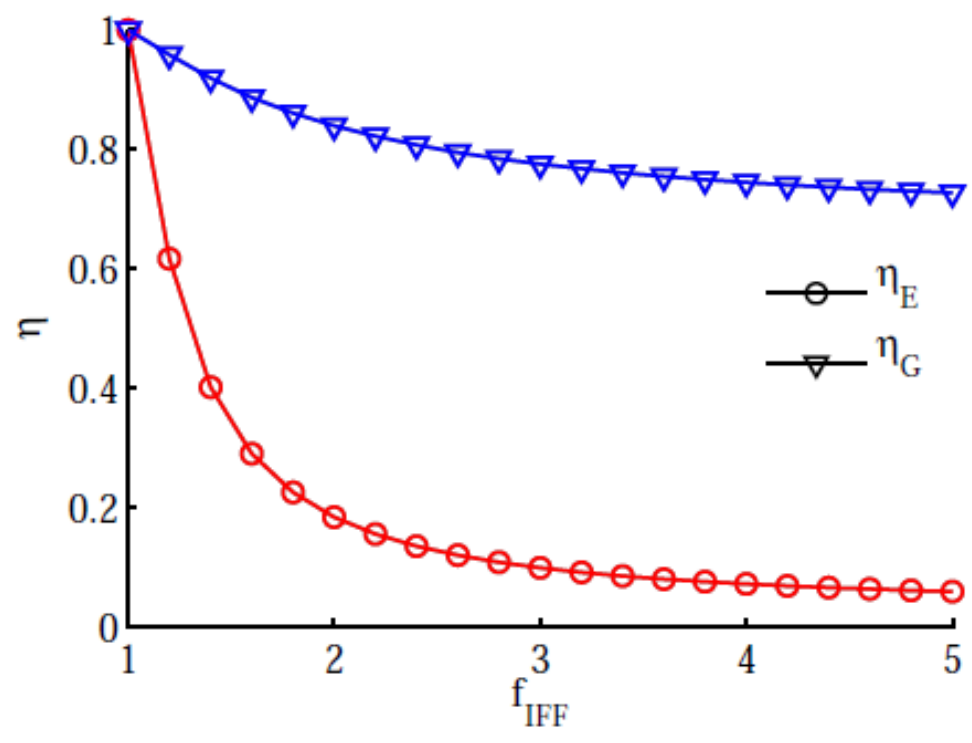

(b)

Figure 3. Degradation parameters: (a) fit curves (FF mode); (b) parameters $\eta$ (IFF modes)[7]

\subsection{Computational Implementation and Parameters Calibration}

The material model proposal was imp lemented as a Fortran subroutine for imp lic it finite element code, using UMAT (Us er Material Subroutine), which was linked to software Abaqus ${ }^{\text {TM }}$. Figure 4 shows the method used during the parameters calibration process, where a program in MatLab was developed in order to carry out automatically this procedure.

As flexural loadings are very important during low velocity impact on composite structures, two material model parameters were calibrated, considering these loadings, before to be used in the explic it finite element analys es. Finally, after a comp lete degradation the respective elements are retained with almost ze ro stiffness to avoid numerical issues. 


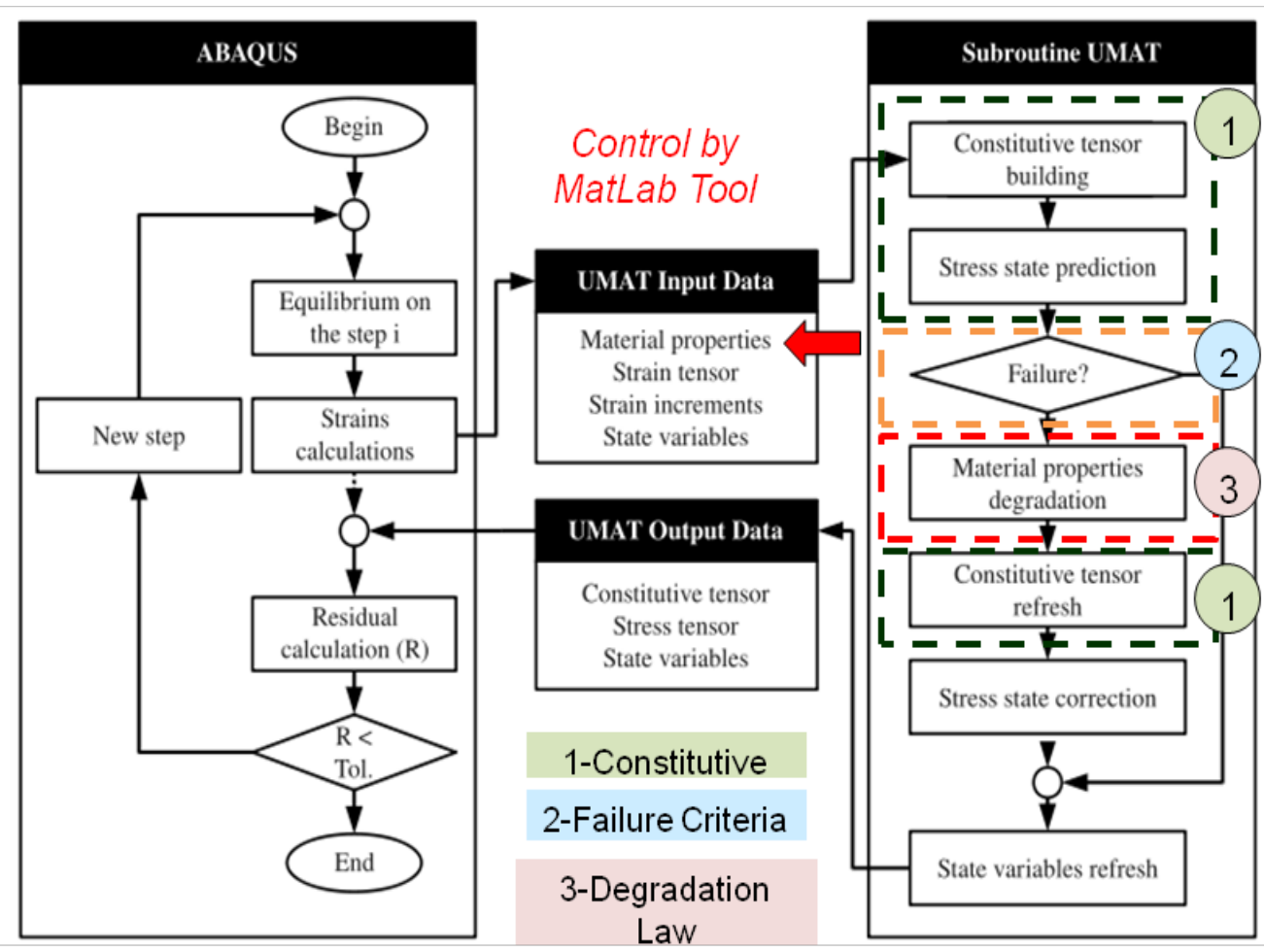

Figure 4. Methodology used for parameters calibration

\section{Finite Element Models}

Two groups of Finite Element (FE) models were developed in this work. The first group simulates three-point bending tests of $[0]_{10}$ and $[0 / 90 / 0 / 90 / 0]_{\mathrm{s}}$ laminates, i.e. implicit finite element analyses. This group was used not only to evaluate the material model proposal (implemented via UMAT), but also to calib rate material model parameters $m$ and $e$ related to the degradation of material properties due to fiber failure mode (FF). The second FE models group simu lates impact test on a composite disk, i.e. exp lic it fin ite element analyses. This group was used to evaluate the limitation and advantages of the material model proposal (implemented via VUMAT), considering the influence not only of the torque value on the screws of the composite disk fixation device, but also the friction coefficient between the composite disk and the fixation device.

\subsection{Three Point Bending Finite Element Model}

These FE models consist on a flat composite plate (made of UD prepreg M10) to simu late 3-point bending test. Table 2 shows the material elastic properties and the strength values used in the implicit nu merical simu lations.

The flat plate had $80 \mathrm{~mm}$ of length, $25 \mathrm{~mm}$ of width and span of $58 \mathrm{~mm}$ between supports (Figure 5). The supports had diameter of $8 \mathrm{~mm}$ and were considered rigid. For boundary conditions, all the degrees of freedom of the two external rig id surfaces were restricted at the reference points (Figure 5). A prescribed displacement of $8 \mathrm{~mm}$ in $\mathrm{z}$ direction was applied at the reference point of the middle rigid surface (Figure 5). Hard contact law implemented at Abaqus ${ }^{\mathrm{TM}}$ was used to simulate the normal interactions between the laminate shell and rigid surfaces of the 3-point bending device. The step size for initial increment was equal $1 \%$ for maximum increment and, equal $3 \%$ of the total prescribed displacement.

Table 2. Elast ic propert ies and strength values[4,9]

\begin{tabular}{ll}
\hline Elastic Properties & Value \\
\hline $\mathrm{E}_{11}$ (Young modulus in 1-direction) & $127 \mathrm{GPa}$ \\
$\mathrm{E}_{22}$ (Young modulus in 2-direction) & $10 \mathrm{GPa}$ \\
$\mathrm{E}_{33}$ (Young modulus in 3-direction) & $10 \mathrm{GPa}$ \\
$\mathrm{G}_{12}$ (Shear modulus in plane 1-2) & $5.4 \mathrm{GPa}$ \\
$\mathrm{G}_{13}$ (Shear modulus in plane 1-3) & $5.4 \mathrm{GPa}$ \\
$\mathrm{G}_{23}$ (Shear modulus in plane 2-3) & $3.05 \mathrm{GPa}$ \\
$v_{12}$ (Poisson's ratio 1-2) & 0.34 \\
$v_{13}$ (Poisson's ratio 1-3) & 0.34 \\
$v_{23}$ (Poisson's ratio 2-3) & 0.306 \\
\hline Strength & Value \\
\hline $\mathrm{X}_{\mathrm{T}}$ (Tensile strength in 1-direction) & $1400 \mathrm{MPa}$ \\
$\mathrm{X}_{\mathrm{C}}$ (Compression strength in 1-direction) & $930 \mathrm{MPa}$ \\
$\mathrm{Y}_{\mathrm{T}}$ (Tensile strength in 2-direction) & $47 \mathrm{MPa}$ \\
$\mathrm{Y}_{\mathrm{C}}$ (Compression strength in 2-direction) & $130 \mathrm{MPa}$ \\
$\mathrm{Z}_{\mathrm{T}}$ (Tensile strength in 3-direction) & $62.3 \mathrm{MPa}$ \\
$\mathrm{S}_{12}$ (Shear strength in plane 1-2) & $53 \mathrm{MPa}$ \\
$\mathrm{S}_{13}$ (Shear strength in plane 1-3) & $53 \mathrm{MPa}$ \\
$\mathrm{S}_{23}$ (Shear strength in plane 2-3) & $89 \mathrm{MPa}$ \\
\hline
\end{tabular}

The finite element mesh is generated by shell elements with full integration (S4) and three integration points through the thickness for each layer. Figure 5 shows the finite element model, where the equilibrium is considered on deformed configuration. Also, the fin ite element analyses are 
performed by the control of the displacement of the load applicator at the middle-span. Two stacking sequences were evaluated in order to calibrate the material model parameters. Laminate 1 had $1.73 \mathrm{~mm}$ of total thickness and stacking sequence equal[0] 0$]_{10}$. Laminate 2 had $1.77 \mathrm{~mm}$ of total thickness and stacking sequence equal $[0 / 90 / 0 / 90 / 0]_{s}$.

\subsection{Impact Finite Element Model}

These FE models consist on a flat composite plate (made of UD prepreg M10) under low velocity impact. Table 2 shows the material elastic properties and the strength values used in the explicit numerical simu lations. In addition, it was used the parameters calibrated by the three point bending analys es. It is important to highlight that the impact analyses follow guidelines provided by standard ASTM D5628-9[11].

The composite specimen was simulated by using shell elements with full integration (S4) and three integration points through the thickness for each layer (Figure 6). Also, it was modelled the whole coupon fixture in order to have more realistic boundary conditions (Figure 6). For the steel fixture discs, it was used 8 nodes linear hexahedron elements with full integration (C3D8). All the displacements degrees of freedom of the lower metal disc were restricted. The screws of the device were simu lated by using 8 nodes linear brick elements with reduced integration (C3D8R). Thus, in order to investigate the influence of the torque on the screw, a small $\mathrm{Uz}$ displacement was applied to simulate the screw compression forces on the fixture steel disks. For $27 \mathrm{Nm}$ and $50 \mathrm{Nm}$ of torque, the $\mathrm{Uz}$ displacement is equal $-0.157 \mathrm{~mm}$ and $-0.291 \mathrm{~mm}$, respectively. The normal interaction between the composite plate and fixtures was simulated using a hard contact law. A penalty contact algorithm with a specific friction coefficient was applied to simulate the tangential interaction. Thus, in order to simulate the influence of this parameter, two reasonable values $(0.1$ and $0.3)$ were selected to simulate the friction between composite plate and steel fixture disks. The same interaction properties were applied to simulate the contact between the impactor and composite plate.

The mass of $1.2 \mathrm{Kg}$, which corresponds to the total of impact mass, was simulated applying this value at the impactor reference point. At this point, an initial velocity of $3.130 \mathrm{~m} / \mathrm{s}$ is also imposed. The impactor was modelled by 4 nodes rigid bilinear quadrilateral element (R3D4).

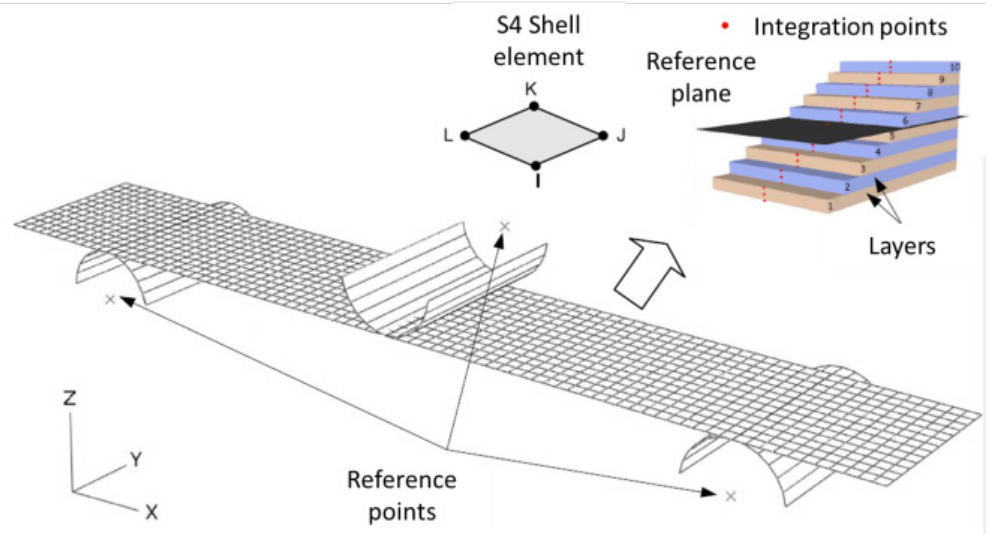

Figure 5. Three point bending FE model: mesh, boundary conditions and element integration points

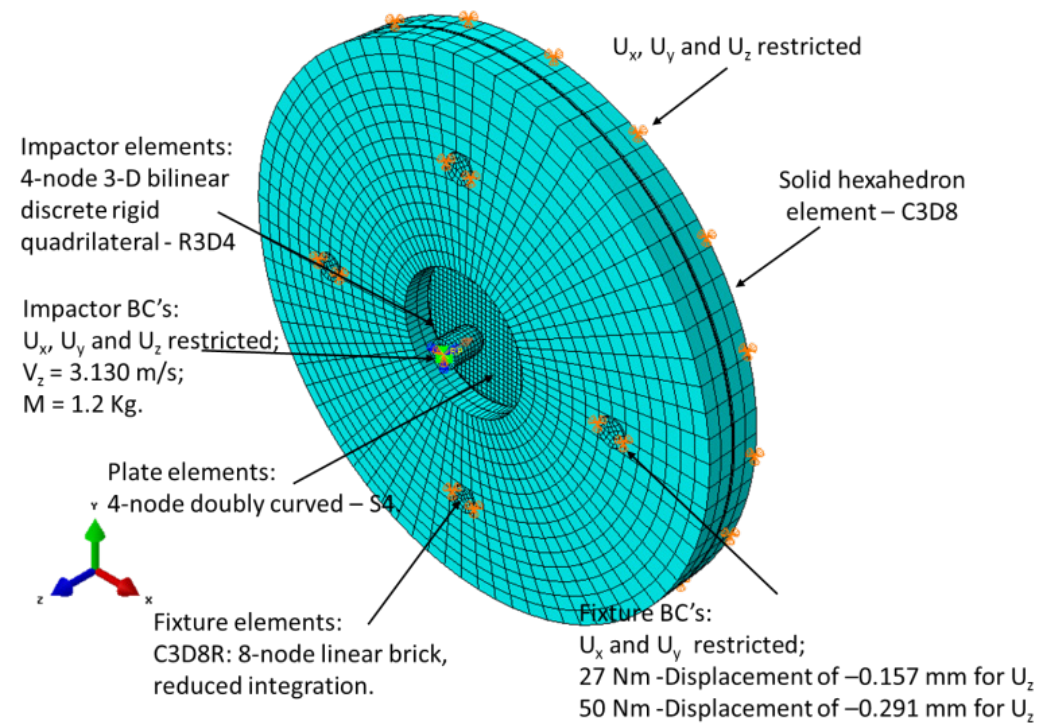

Figure 6. Impact test FE model: mesh, boundary conditions and initial conditions 


\section{Results}

\subsection{Results for Three Point Bending Analyses}

Figure 7(a) shows the FE results for $[0]_{10}$ (Laminate 1) and Figure 7(b), for[0/90/0/90/0 $]_{\mathrm{s}}$ (Laminate 2). The shaded areas correspond to the experimental test envelop. Also, it is shown the numerical results provided by another material model[4].
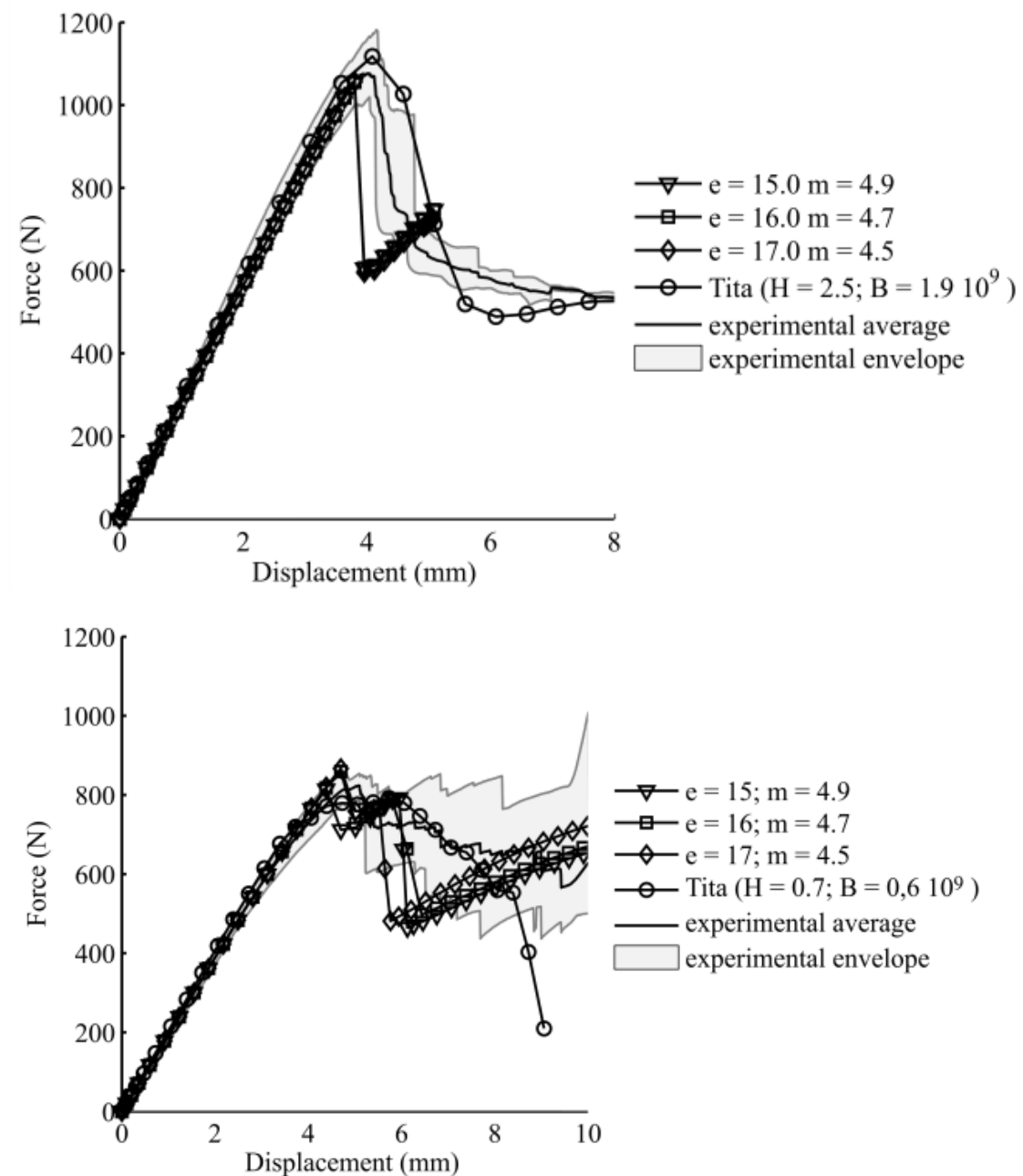

(b)

Figure 7. Parameters calibration: (a) unidirectional $0^{\circ}-[0]_{10}$; (b) cross-ply laminate-[0/90/0/90/0]s.

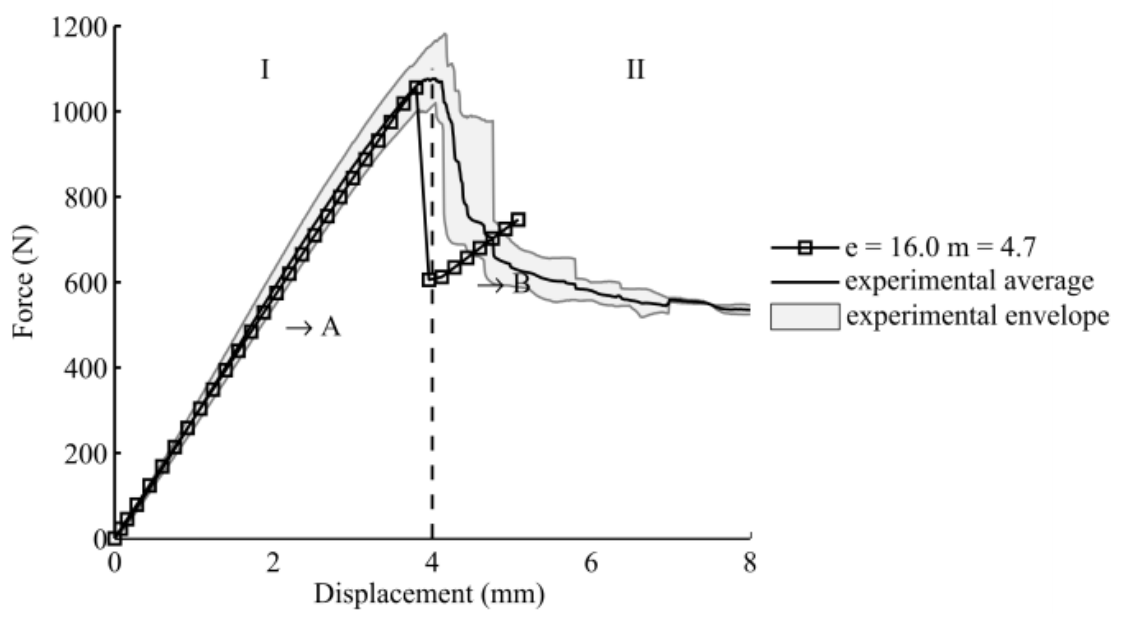

(a) 


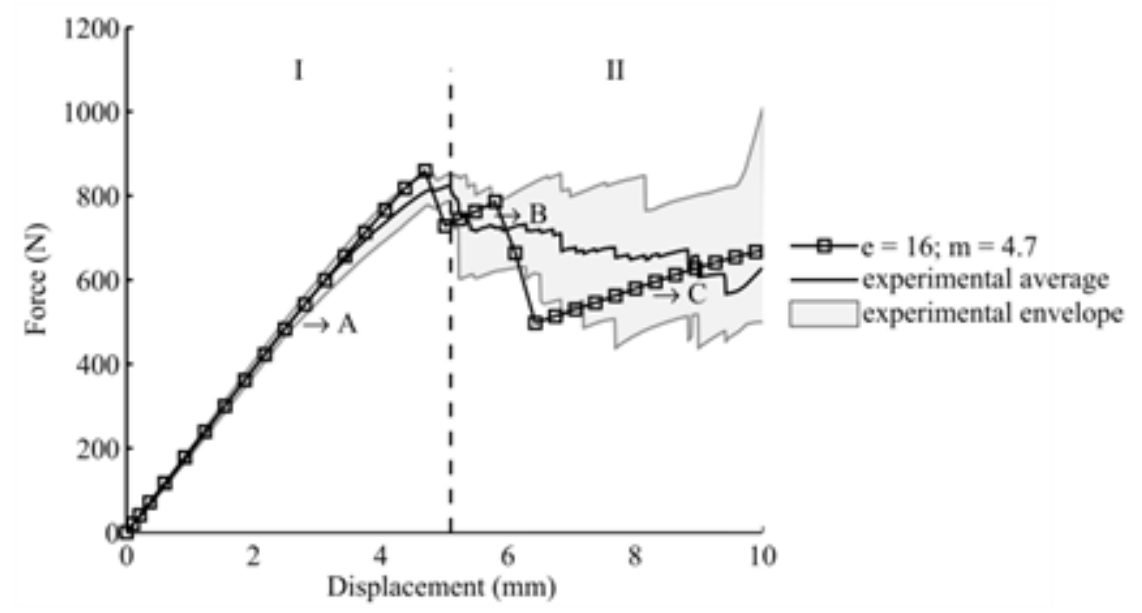

(b)

Figure 8. Three point bending test s and numerical simulations: (a) $[0]_{10}$; (b) $[0 / 90 / 0 / 90 / 0]_{\text {s. }}$

After some implicit simu lations, it is possible to select more adequate values for the parameters via calibration process via the program in MatLab. For instance, Figure 8 shows a comparison between experimental and FE results provided by the material model proposal, considering $e$ equal 16.0 and $m$ equal 4.7. It is important to highlight that these values were used in the impact numerical analyses. As commented earlier, this strategy was applied, because the low impact velocity tests are driven by flexural loadings. Thus, this is one of the reasons that three-point bending tests were selected to calibrate the parameters of the material model proposal. There are other reasons for using three point bending tests, such as, it is a simple test to be carried out and it is not so complicated to manufacture the composite specimens.

\subsection{Results for Impact Analyses}

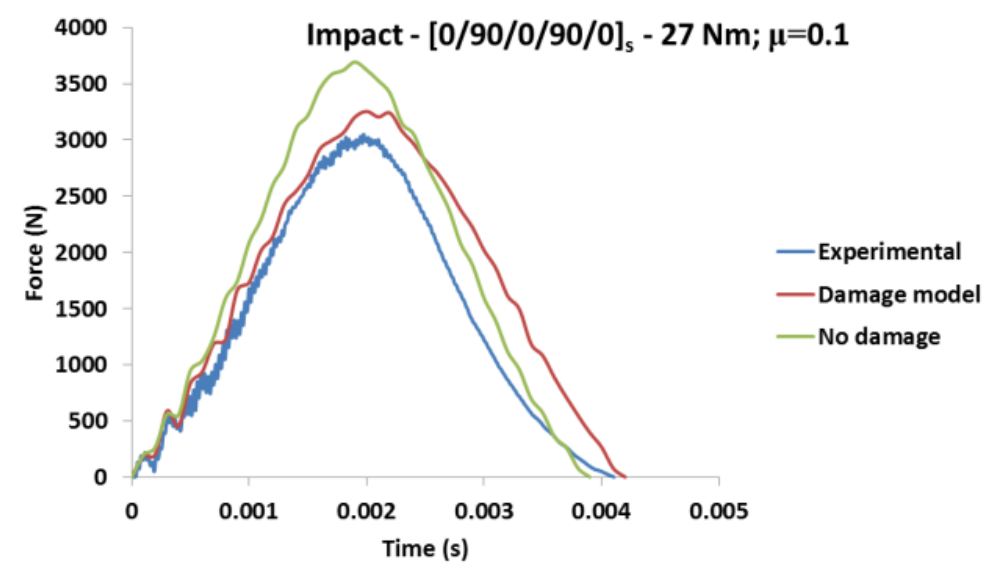

(a)

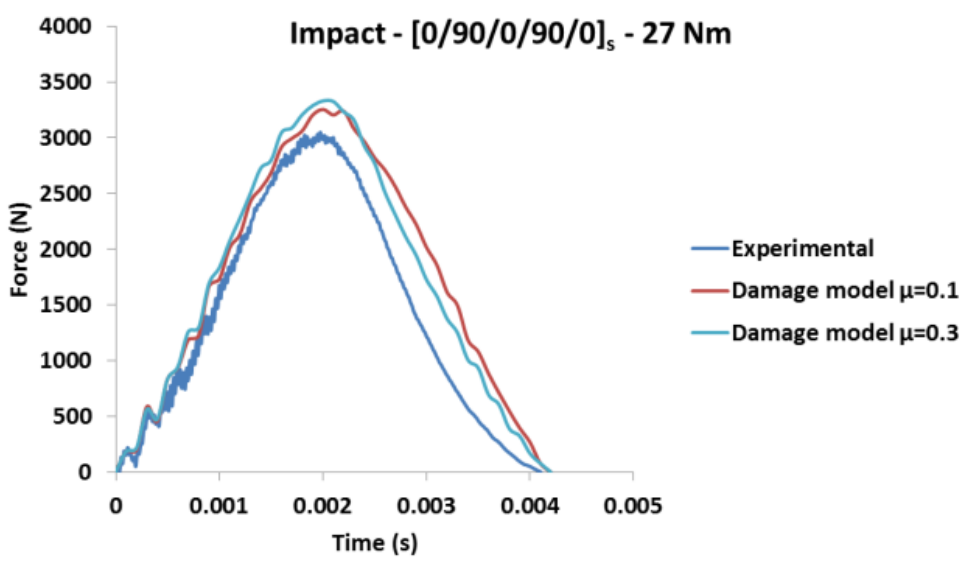

(b)

Figure 9. [0/90/0/90/0 $]_{\mathrm{s}}$ force $v s$. time impact results for $27 \mathrm{Nm}$ of torque: (a) Experimental, undamaged and damage simulations results; ( b) Friction coefficient influence on numerical analyses 
Figure 9(a) shows force-time graphics for thin composite disk with stacking sequence $[0 / 90 / 0 / 90 / 0]_{\mathrm{s}}$, under $5.91 \mathrm{~J}$ impact energy and $27 \mathrm{Nm}$ of torque on screws of the fixture device. In the experimental data, there is a region with oscillations of high frequency (from 0 until $1.2 \mathrm{~ms}$ ). From $1.8 \mathrm{~ms}$, there are some small oscillations, which show damage process. Due to the stacking sequence $[0 / 90 / 0 / 90 / 0]_{\mathrm{s}}$ (cross-ply laminate), the main failure mechanis ms are the matrix rupture and delaminations, which reduces the global stiffness of the structure. Therefore, there is not abrupt drop of the impact force value after the progressive damage process initiation.

The FE analyses via Abaqus ${ }^{\mathrm{TM}}$ using the material model proposal (implemented via VUMAT) were able to simulate the initial oscillations of the impact (from 0 until $0.5 \mathrm{~ms}$ ). By the other side, the numerical simu lations via Abaqus ${ }^{\mathrm{TM}}$ with no damage were also capable to simulate those initial oscillations. However, the maximum peak force is closer to the experimental maximum value when is used the material model proposal. The duration of the impact event is around $4.1 \mathrm{~ms}$ for the experimental test, $4.2 \mathrm{~ms}$ for the damaged model and $3.9 \mathrm{~ms}$ for the undamaged model (Figure
9(a)).The influence of friction coefficient was also studied. The results for friction coefficient $(\mu) 0.1$ and 0.3 are shown in Figure 9(b). It is observed that the higher friction coefficient increases a little the maximum force peak. This increasing is due to the tangential interaction forces between the fixture and composite plate, where higher friction coefficient produces higher tangential reaction forces.

Table 3 shows results for the composite disk with stacking sequence[0/90/0/90/0 $]_{\mathrm{s}}$ and $27 \mathrm{Nm}$ of torque on screws, as well as co mparisons between experimental and FE results.

Table 3. Results for torque of $27 \mathrm{Nm}-[0 / 90 / 0 / 90 / 0]_{\mathrm{s}}$

\begin{tabular}{ccccc}
\hline & $\begin{array}{c}\text { Max Force } \\
(\mathbf{N})\end{array}$ & $\begin{array}{c}\text { Error* } \\
\mathbf{\%}\end{array}$ & $\begin{array}{c}\text { Time } \\
(\mathbf{m s})\end{array}$ & $\begin{array}{c}\text { Error* } \\
\mathbf{\%}\end{array}$ \\
\hline Experimental & 3048 & - & 4.1 & - \\
Damage $\mu=0.1$ & 3252 & 6.7 & 4.2 & 2.4 \\
Damage $\mu=0.3$ & 3329 & 9.2 & 4.2 & 2.4 \\
Undamaged & 3691 & 21.1 & 3.9 & 4.9 \\
\hline
\end{tabular}

$*$ Error $=\mid($ Experimental - Simulations $) /$ Experimental $\mid$

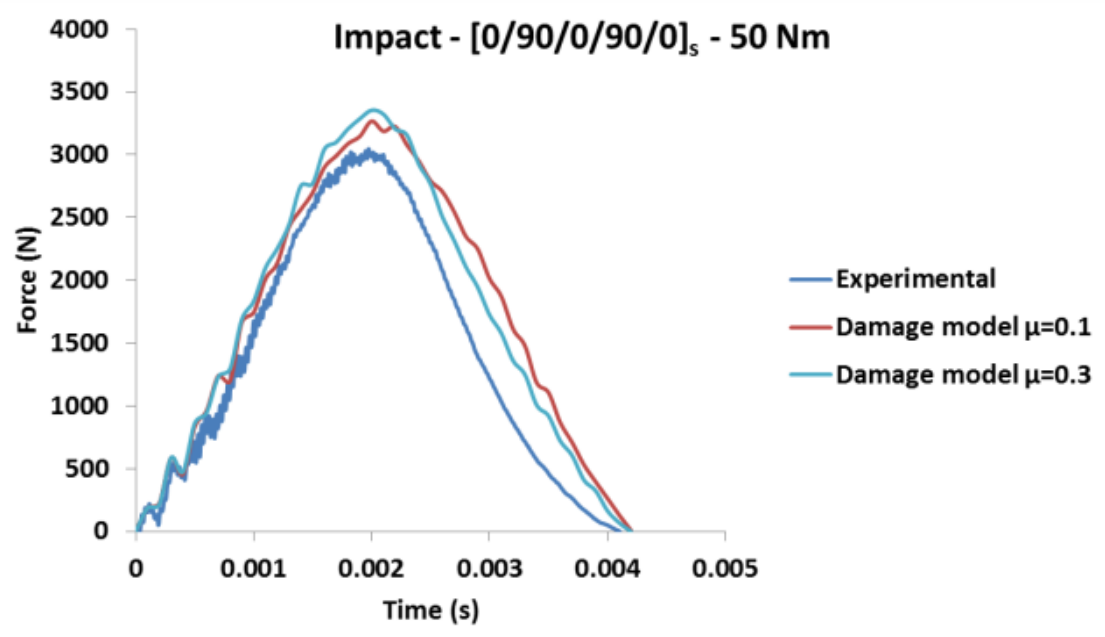

(a)

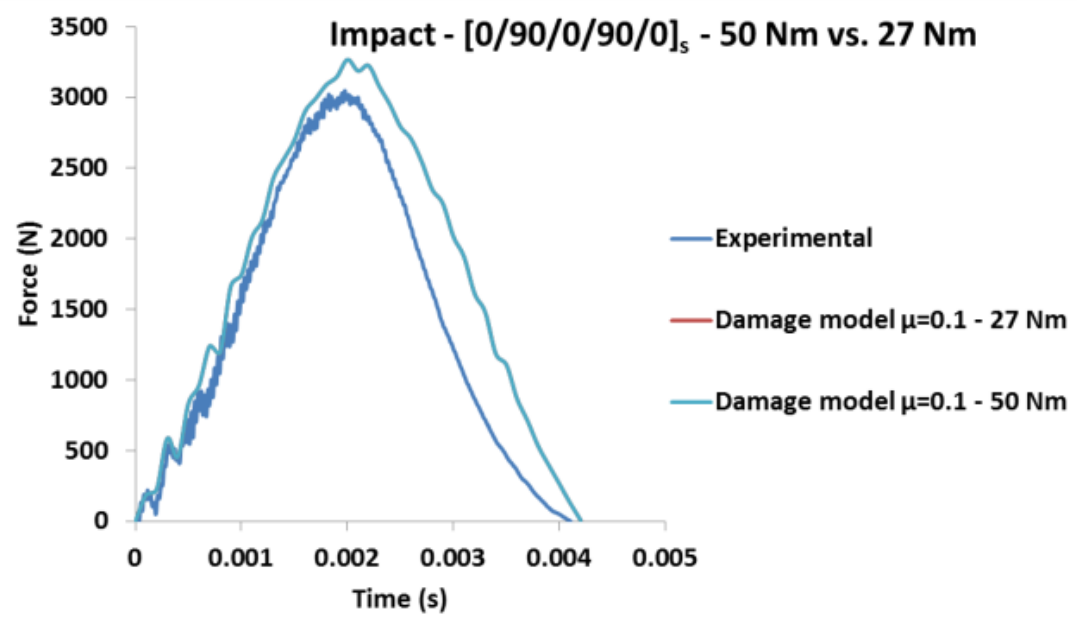

Figure 10. [0/90/0/90/0 $]_{s}$ force $v s$. time impact results for $27 \mathrm{Nm}$ of torque: (a) Experimental, undamaged and damage simulations results; (b) Friction coefficient influence on numerical analyses 
Figure 10(a) shows the results for thin composite disk with stacking sequence $[0 / 90 / 0 / 90 / 0]_{s}$, regarding the different friction coefficients and $50 \mathrm{Nm}$ of torque on screws. As for the previous case, for lower friction coefficient, the model had the force peak decreased a little bit. Figure 10(b) shows that there are not any difference between the results for $27 \mathrm{Nm}$ and $50 \mathrm{Nm}$ of torque. Thus, for the next $\mathrm{FE}$ analyses, it is assumed that the torque value is equal $27 \mathrm{Nm}$, but different values for the friction coefficient are still considered (0.1 and 0.3$)$.

Figure 11(a) shows force-time graphics for composite disk with stacking sequence[0 $]_{10}$ under $5.91 \mathrm{~J}$ impact energy. The experimental data shows high frequency oscillations in the beginning of the impact event, as well as some lower frequency oscillations (from $0 \mathrm{~ms}$ until $0.5 \mathrm{~ms}$ ), which was not simulated by the FE models.

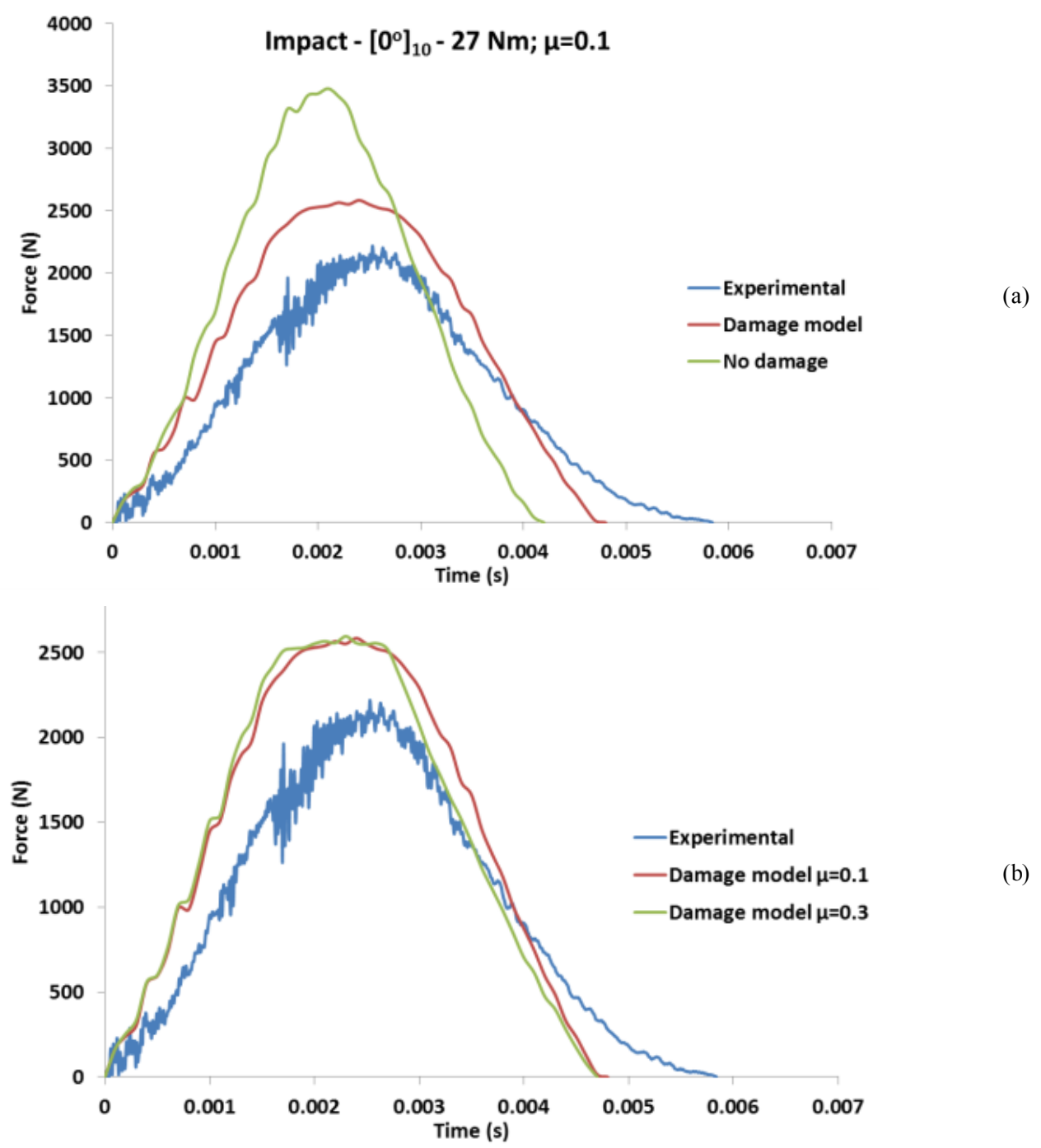

Figure 11. $[0]_{10}$ force $v s$.time impact results for $27 \mathrm{Nm}$ of torque: (a) Experimental, undamaged and damage simulations results; (b) Friction coefficient influence on numerical analyses

Table 4. Results for torque of $27 \mathrm{Nm}-[0]_{10}$

\begin{tabular}{ccccc}
\hline & $\begin{array}{c}\text { Max Force } \\
(\mathbf{N})\end{array}$ & $\begin{array}{c}\text { Error* } \\
\mathbf{\%}\end{array}$ & $\begin{array}{c}\text { Time } \\
(\mathbf{m s})\end{array}$ & $\begin{array}{c}\text { Error* } \\
\mathbf{\%}\end{array}$ \\
\hline Experimental & 2217 & - & 5.8 & - \\
Damage $\mu=0.1$ & 2583 & 16.5 & 4.8 & 20.8 \\
Damage $\mu=0.3$ & 2595 & 17.0 & 4.8 & 20.8 \\
Undamaged & 3478 & 28.1 & 4.2 & 38.1 \\
\hline
\end{tabular}

*Error $=\mid($ Experimental - Simulations $) /$ Experimental $\mid$

Despite the others lay-up shown in this work, the $0^{\circ}$ lay-up shows an abrupt drop on the force around $1.8 \mathrm{~ms}$. For this laminate, failure mechanis ms are more severe than for the previous cases. For example, fiber breakage absorbs much more energy than matrix damage[10]; so the force peak is lower and the impact duration is bigger for this laminate.

The friction coefficient had a little effect on the numerical results for $[0]_{10}$ laminates as shown by Figure 11(b). The model with 0.3 friction coefficient resulted in a maximum reaction force, i.e. only $12 \mathrm{~N}$ greater than the model with 0.1 friction coefficient (less than $0.5 \%$ of the maximum force).

Table 4 shows results for the composite disk with stacking sequence $[0]_{\mathrm{s}}$ and $27 \mathrm{Nm}$ of torque on screws, as well as comparis ons between experimental and FE results. For this 
laminate, the deviations of $\mathrm{FE}$ results fro $\mathrm{m}$ the experimental result are greater than for the cross-ply laminates $[0 / 90 / 0 / 90 / 0]_{\mathrm{s}}$ regardless the friction coefficient. However, it is possible to observe that the material model proposal improves the finite element results, mainly the prediction of maximum force.

Finally, Figure 12(a) shows force-time graphics for composite disks with stacking sequence $[+45 /-45 /+45 / 0 / 90]_{\mathrm{s}}$ under $5.91 \mathrm{~J}$ impact energy. The quasi-isotropic laminate behaves rather similar to cross-ply laminates. For the experimental data, there is a region with oscillations of high frequency (from 0 until $1.2 \mathrm{~ms}$ ). From $1.8 \mathrm{~ms}$, there are some small oscillations, which show damage process. As for the cross-ply laminate, the main failure mechanisms are the matrix rupture and delaminations, which reduce the global stiffness of the structure. Therefore, there is no abrupt drop of the impact force value after the progressive damage process initiation. The FE analyses with the proposed material model were capable to simulate the initial oscillations of the impact (fro $\mathrm{m} 0$ until $0.2 \mathrm{~ms}$ ).

By the other side, the numerical simulations with undamaged model were also capable to simulate those initial oscillations. For this laminate, the maximum peak force provided by the proposed material model as well as estimated by the model with no damage are not so close to the experimental maximum value. The duration of the impact event is around $4.0 \mathrm{~ms}$ for the experimental, $3.8 \mathrm{~ms}$ for the damage model and $3.8 \mathrm{~ms}$ for the undamaged model (Figure 12(a)).

For this lay-up as for $[0]_{10}$ laminate, the friction coefficient used to model the tangential behavior by the contact algorith $m$ did not affect the impact response (Figure 12 (b)). The difference due to friction coefficient is only $36 \mathrm{~N}$, i.e. less than $1 \%$ of the maximum simulation force.

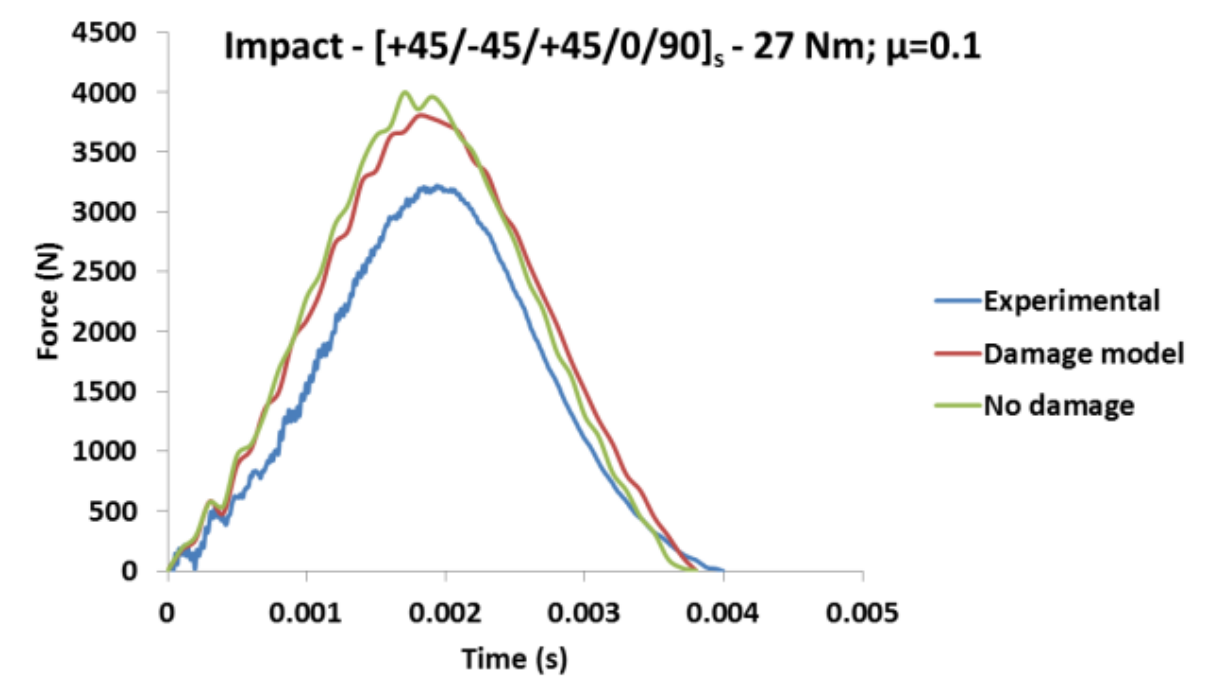

(a)

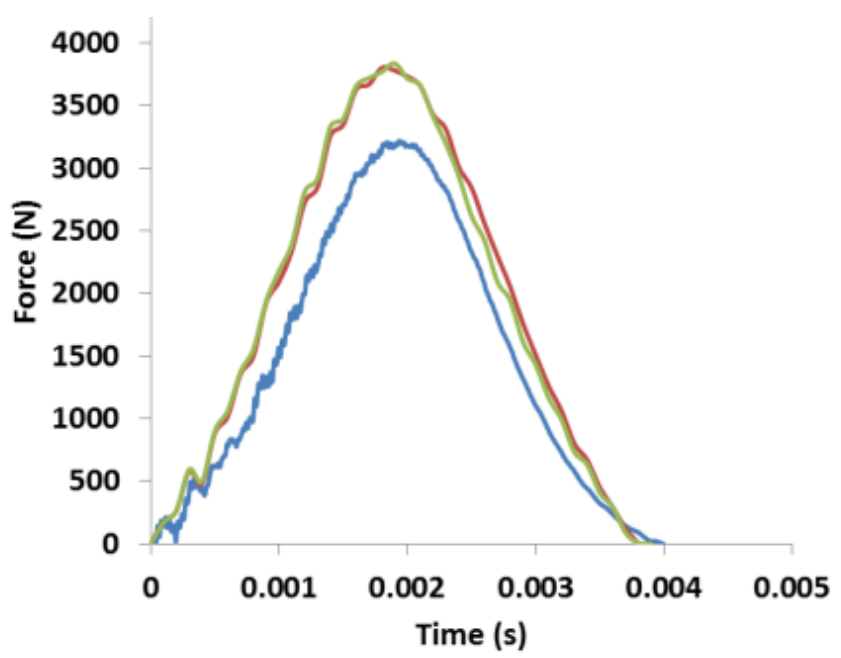

Figure 12. [ $+45 /-45 / 0 / 90]_{s}$ force $v s$. time impact results for $27 \mathrm{Nm}$ of torque: (a) Experimental, undamaged and damage simulations results; (b) Friction coefficient influence on numerical analyses 
Table 5 shows results for the composite disk with stacking sequence[ $[+45 /-45 / 0 / 90]_{\mathrm{s}}$ and $27 \mathrm{Nm}$ of torque on screws, as well as comparisons between experimental and FE results.

Table 5. Results for torque of $27 \mathrm{Nm}-[+45 /-45 / 0 / 90]$

\begin{tabular}{|c|c|c|c|c|}
\hline & $\begin{array}{c}\text { Max } \\
\text { Force }(\mathbf{N})\end{array}$ & $\begin{array}{c}\text { Error* } \\
\%\end{array}$ & $\begin{array}{l}\text { Time } \\
(\mathrm{ms})\end{array}$ & $\begin{array}{c}\text { Error* } \\
\%\end{array}$ \\
\hline Experimental & 3218 & - & 4.0 & - \\
\hline $\begin{array}{c}\text { Damage } \\
\mu=0.1\end{array}$ & 3800 & 18.1 & 3.8 & 4.9 \\
\hline $\begin{array}{c}\text { Damage } \\
\mu=0.3\end{array}$ & 3836 & 19.2 & 3.8 & 4.9 \\
\hline Undamaged & 3955 & 24.1 & 3.6 & 9.9 \\
\hline
\end{tabular}

*Error $=\mid($ Experimental - Simulations $) /$ Experimental $\mid$

\section{Conclusions}

The material model proposal is a new failure model because consists on a co mbination ofd ifferent failure criteria and damage evolution law. The parameters associated to the degradation of the material properties due to fiber failure were deeply investigated. It can be concluded that the investigation of these parameters is fundamental to understand how it affects the structural behavior, as well as the relevance of one parameter in relation to the others. Also, it can be concluded that the calibration process of the parameters related to the composite material model needs to be consider for different stacking sequences.

Regardless the difficulties related to three point bending tests (matrix crushing under the load applier), the material model performed good numerical predictions for this quasi-static case. However, the simulation for an impact event represents a bigger challenge. As it can be observed, the proposed material model could predict very well the behavior of cross-ply laminates, determining with accuracy the maximum force peak and the impact duration. On the other hand, the model performance for the others lay-up was not so good with error higher than $16 \%$ for force peak. This can be partially explained through the calibration process, which is better performed for cross-ply laminate. Another reason for the poor model accuracy is due to lack of delamination criteria. The simulation of this phenomenon is essential for laminates, which presents mainly delaminations during impact events.

A parametric investigation regarding the applied torque on the fixture screws has shown that the influence on the results was low for the applied values. Other parametric study presented the effect of tangential friction coefficient used on the Abaqus ${ }^{\mathrm{TM}}$ contact algorithm. Based on the FE results, it is possible to conclude that the friction coefficient has a small influence on the numerical simulations, considering the investigated values.

\section{ACKNOWLEDGEMENTS}

The authors are grateful for the support fro m CTM (Navy Technological Center - Brazil), São Paulo Research Foundation (FAPESP process number: 2009/00544-5), National Council of Research (CNPq process number: 208137/2012-2), AFOSR and US-Army (Grant/Contract Number: FA9550-10-1-0011). The authors also would like to thank Prof. Reg inaldo Teixeira Coe lho (São Carlos School of Engineering - University of São Paulo) for providing the Abaqus ${ }^{\mathrm{TM}}$ license.

\section{REFERENCES}

[1] C. M. Kindervater and H. Georgi, "Composite strength and energy absorption as an aspect of structural crash resistance," Structural crashworthiness and failure, pp. 189-235, 1993.

[2] M. Sari, R. Karakuzu, M. E. Deniz, and B. M. Icten, "Residual failure pressures and fatigue life of filament-wound composite pipes subjected to lateral impact," Journal of Composite Materials, vol. 46, no. 15, pp. 1787-1794, 2012.

[3] M. L. Ribeiro, V. Tita, and D. Vandepitte, "A new damage model for composite laminates," Composite Structures, vol. 94, no. 2, pp. 635-642, 2012.

[4] V. Tita, J. Carvalho, and D. Vandepitte, "Failure analysis of low velocity impact on thin composite laminates: Experimental and numerical approaches," Composite Structures, vol. 83, no. 4, pp. 413-428, 2008.

[5] Z. Hashin, "Failure Criteria for Unidirectional Fiber Composites," Journal of Applied Mechanics, vol. 47, no. 2, pp. 329-334, 1980.

[6] A. Puck and H. Schürmann, "Failure analysis of FRP laminates by means of physically based phenomenological models," Composites Science and Technology, vol. 58, no. 7, pp. 1045-1067, 1998.

[7] A. Puck and H. Schürmann, "Failure analysis of FRP laminates by means of physically based phenomenological models," Composites Science and Technology, vol. 62, no. 12-13, pp. 1633-1662, 2002.

[8] A. Matzenmiller, J. Lubliner, and R. L. Taylor, "A constitutive model for anisotropic damage in fiber-composites," Mechanics of Materials, vol. 20, no. 2, pp. 125-152, 1995.

[9] V. Tita, "Contribution to the study of damage and progressive failure analyses of composite structures," $\mathrm{PhD}$ Thesis, São Carlos School of Engineering, University of São Paulo, 2003 (in Portuguese).

[10] S. Abrate, "Modeling of impacts on composite structures," Composite Structures, vol. 51, no. 2, pp. 129-138, 2001.

[11] American Society for Testing Materials. D5628-96: standard test method for impact resistance of flat, rigid plastic specimens by means of a falling dart (tup or falling mass). Philadelphia, 1996. 